\title{
Intra-atrial rerouting by transference of the posterior left atrial wall for cardiac-type total anomalous pulmonary venous return
}

\author{
Masaaki Yamagishi, MD, Keisuke Shuntoh, MD, Akiyuki Takahashi, MD, Takeshi Shinkawa, MD, Takako Miyazaki, MD, \\ and Nobuo Kitamura, MD, Kyoto, Japan
}

$\mathrm{T}$ he conventional surgical techniques for total anomalous pulmonary venous return (TAPVR) with direct drainage of the pulmonary veins (PVs) into the coronary sinus are the cutback method ${ }^{1}$ and the Van Praagh technique. ${ }^{2}$ We developed an alternative technique for cardiac-type TAPVR without using a prosthetic patch or an autologous pericardium.

\section{Clinical Summary}

A male infant weighing $5490 \mathrm{~g}$ was referred to our hospital for surgical repair. Echocardiography revealed the common PV draining directly into the enlarged coronary sinus and a large atrial septal defect (ASD). There were no stenotic lesions in the PVs. The anterior wall of the common PV was shared with the posterior left atrial wall.

Surgical repair was performed at 5 months of age. During moderate hypothermic cardiopulmonary bypass and aortic crossclamping, the right atrium was incised longitudinally. The coronary sinus was noticeably enlarged. The large ASD was also detected. The anterior edge (Figure 1A, point $b$ ) of the roof of the coronary sinus was incised toward the left atrium. The inferior atrial septum was also incised toward the anteroinferior edge of the ASD. The anterior edge of the left atrial portion of the roof of the coronary sinus was also incised. At the left end of the junction between the coronary sinus and the common PV (Figure 1A, point $d$ ), the direction of the incision was changed to the craniad. Along the left edge of the anterior wall of the common PV channel, which was shared with the posterior left atrial wall, the incision was extended longitudinally. At the left superior edge of the common $\mathrm{PV}$ (Figure 1A, point $e$ ), the direction of the incision was changed to the right. The incision was changed to the caudad at the right superior edge of the common PV channel (Figure 1A, point $f$ ) and was extended to the midpoint between the right superior edge of the common PV and the anterosuperior edge of the coronary sinus (Figure 1A, point $g$ ). Along the section, the intima of the common PV and the left atrial endocardium were joined together with

From the Department of Pediatric Cardiovascular Surgery, Children's Research Hospital, Kyoto Prefectural University of Medicine, Kyoto, Japan.

Received for publication Nov 28, 2001; accepted for publication Dec 9, 2001.

Address for reprints: Masaaki Yamagishi, MD, Department of Pediatric Cardiovascular Surgery, Children's Research Hospital, Kyoto Prefectural University of Medicine, Kawaramachi, Hirokoji, Kamikyo-ku, Kyoto, 6028566 Japan (E-mail: myama@koto.kpu-m.ac.jp).

J Thorac Cardiovasc Surg 2002;123:996-9

Copyright (C) 2002 by The American Association for Thoracic Surgery $0022-5223 / 2002 \$ 35.00+0 \quad \mathbf{1 2 / 5 4 / 1 2 2 4 3 8}$

doi: $10.1067 / \mathrm{mtc} .2002 .122438$ interrupted 6-0 polypropylene sutures (Pronova; Ethicon, Inc, Somerville, NJ). Then a tongue-like flap of the posterior left atrial wall was set upright and anastomosed to the edge of the ASD and a section at the inferior atrial septum with a running 6-0 polydioxanone suture (Ethicon; Figures $1 \mathrm{~B}$ and $1 \mathrm{C}$ ). The right atrial portion of the roof of the coronary sinus was pulled down and anastomosed to the floor of the coronary sinus, taking care not to damage the atrioventricular node. Both suture lines were finally connected. After completion of the intra-atrial rerouting, a wide communication between the common PV and the left atrium was created, and the coronary vein was directly drained into the left atrium (Figure 2).

Postoperative Doppler echocardiography confirmed that the pulmonary venous bloodstream passed without turbulence through the wide communication between the common PV and the left atrium.

\section{Discussion}

The cutback method ${ }^{1}$ is a widely used surgical technique for cardiac-type TAPVR with direct drainage of the PV into the coronary sinus. Another common technique is the Van Praagh technique, ${ }^{2}$ which involves fenestration between the common PV and the left atrium and direct closure of the ASD and coronary sinus. A very serious late complication is pulmonary venous obstruction. ${ }^{3,4}$ Therefore, the communication between the common PV and the left atrium should be made as large as possible. However, with the conventional surgical techniques, the size of the communication is limited, and hence pulmonary venous obstruction cannot be entirely avoided. Compared with the conventional surgical techniques for cardiac-type TAPVR, with our modification there is less risk of pulmonary venous obstruction because the posterior left atrial wall, which separates the common PV from the left atrium, is completely eliminated to provide a sufficiently wide communication for the pulmonary venous channel. A tongue-like posterior left atrial wall flap was set upright and was used to close the interatrial communication. Neither a prosthetic patch nor an autologous pericaridial patch is necessary to accomplish the repair. There may be little possibility of late complication caused by this technique. This technique is also applicable to cardiac-type TAPVR combined with the common PV stenosis at the junction of the coronary sinus.

\section{References}

1. Stark J. Anomalous pulmonary venous return and cor triatriatum. In: Stark J, de Leval M, editors. Surgery for congenital heart defects. 2nd ed. Philadelphia: WB Saunders; 1994. p. 329-42.

2. Van Praagh R, Harken AH, Delisle G, Ando M, Gross RE. Total anomalous pulmonary venous drainage to the coronary sinus: a revised procedure for its correction. J Thorac Cardiovasc Surg. 1972;64:132-5. 


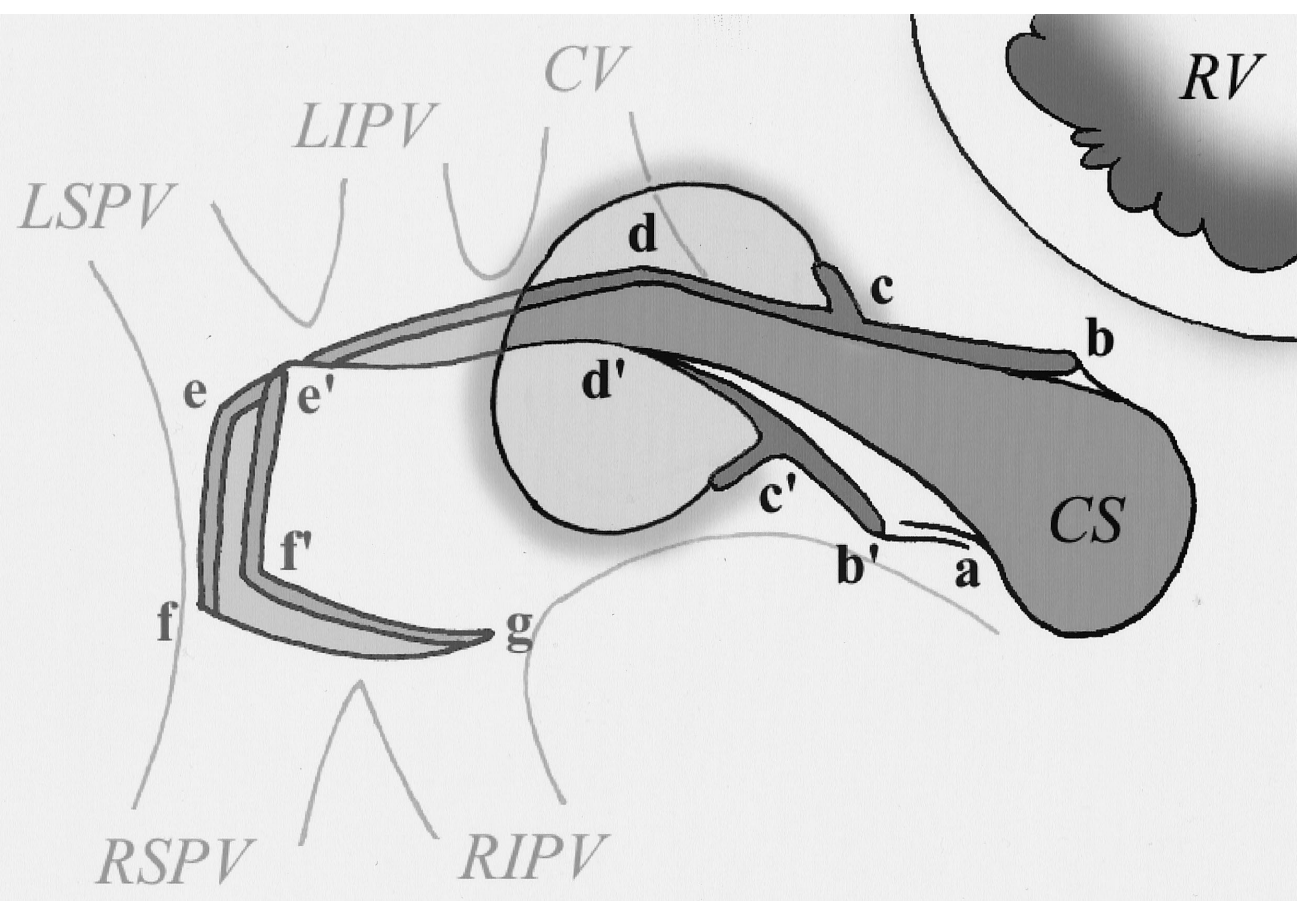

Figure 1A. The coronary sinus was cut back toward the left atrium (line $b$-c-d). A tongue-like flap by the posterior left atrial wall (curved line $d^{\prime}-e^{\prime}-f^{\prime}-g^{\prime}$ ) was cut out. The inferior atrial septum was also incised. CS, Coronary sinus; CV, coronary vein; $L I P V$, left inferior pulmonary vein; $L S P V$, left superior pulmonary vein; RIPV, right inferior pulmonary vein; $R S P V$, right superior pulmonary vein; $R V$, right ventricle.

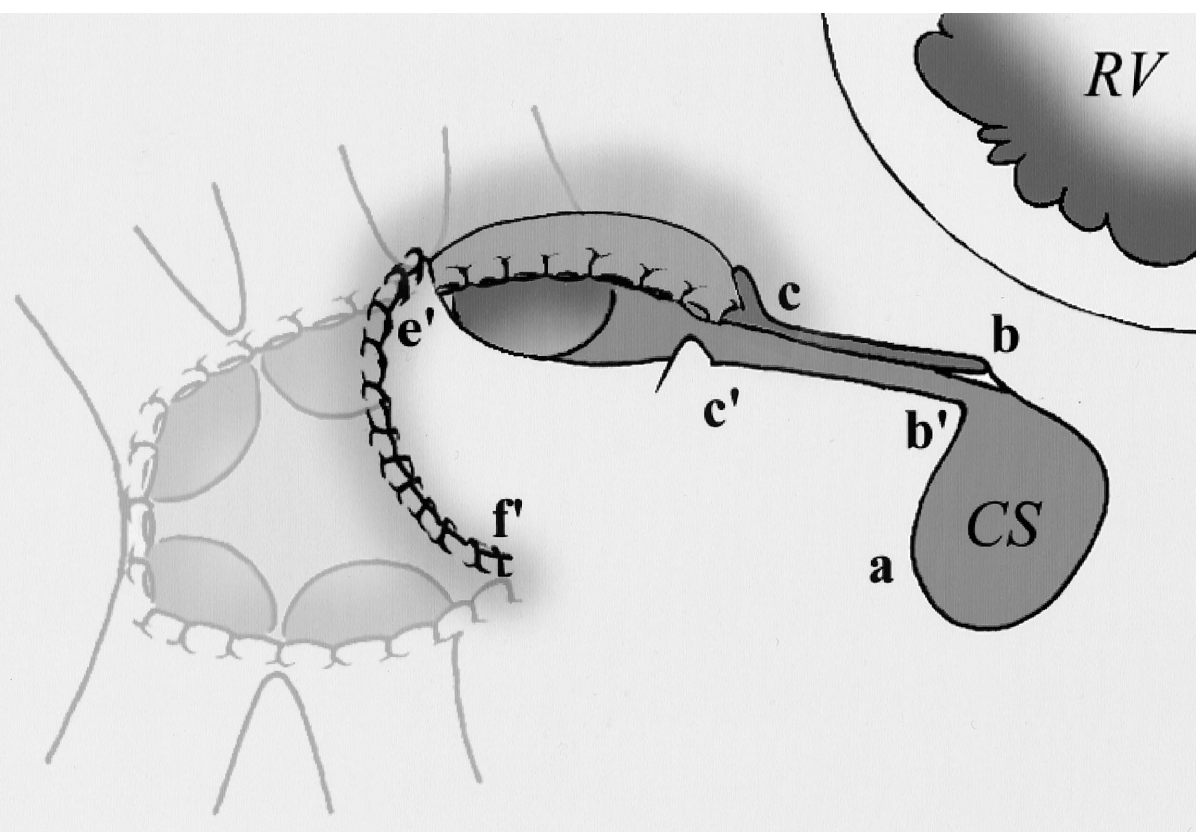

Figure 1B. The posterior left atrial wall flap (curved line $f^{\prime}-e^{\prime}$ ) was set upright and anastomosed to the edge of the ASD. RV, Right ventricle; CS, coronary sinus. 


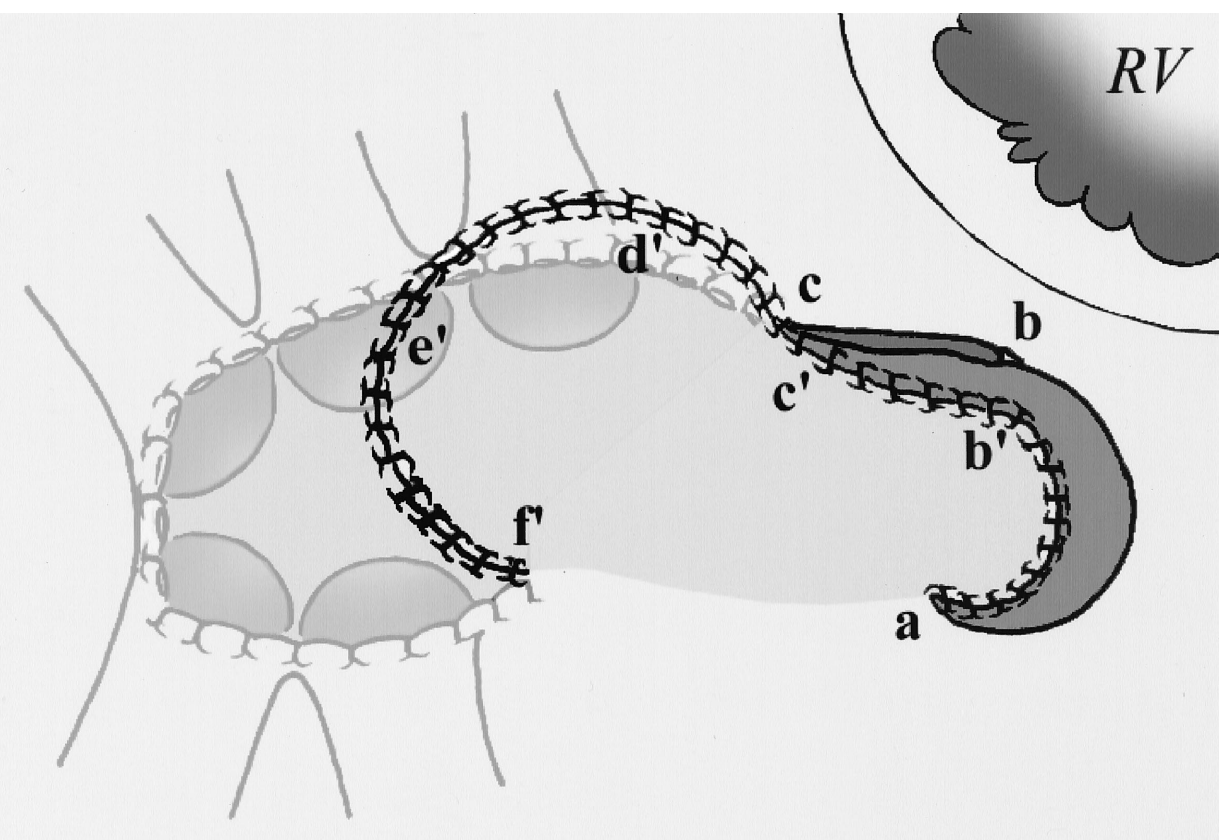

Figure 1C. The ASD was closed by the posterior left atrial wall flap (curved line $f^{\prime}-e^{\prime}-d^{\prime}-c^{\prime}$ ). A large communication between the common PV and the left atrium was created. The right atrial portion of the roof of the coronary sinus (curved line $a-b-c$ ) was pulled down and anastomosed to the floor of the coronary sinus. RV, Right ventricle.

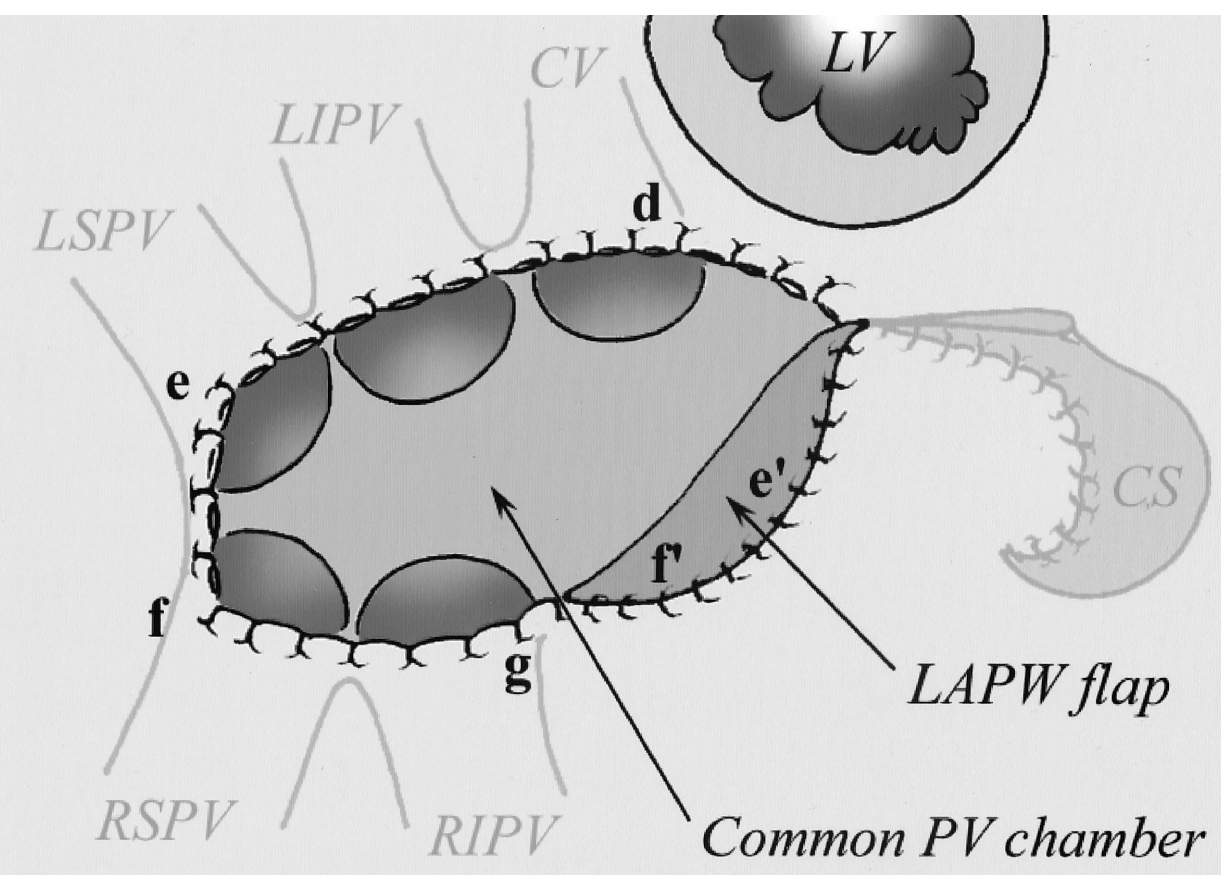

Figure 2. Left atrial view. A wide communication between the common PV and the left atrium was created, and the coronary vein was directly drained into the left atrium. CS, Coronary sinus; CV, coronary vein; LIPV, left inferior pulmonary vein; $L S P V$, left superior pulmonary vein; $R I P V$, right inferior pulmonary vein; $R S P V$, right superior pulmonary vein; $L V$, left ventricle; $L A P W$, left atrial pulmonary wall. 
3. Jonas RA, Smolinsky A, Mayer JE, Castaneda AR. Obstructed pulmonary venous drainage with total anomalous pulmonary venous connection to the coronary sinus. Am J Cardiol. 1987;59: 431-5.
4. Lacour-Gayet F, Zoghbi J, Serraf AE, Belli E, Piot D, Rey C, et al. Surgical management of progressive pulmonary venous obstruction after repair of total anomalous pulmonary venous connection. $J$ Thorac Cardiovasc Surg. 1999;117:679-87. 